\title{
COMUNICAÇÃO
}

\section{ESTUDO SOBRE A EVENTUAL INFLUÊNCIA DA ERVA DE SANTA MARIA NA EVOLUÇÃO E MORTALIDADE DE TRIATOMÍNEOS}

\author{
Hertha Barbara Wüllert Telles de Souza, Vicente Amato Neto, \\ Lucia Maria Almeida Braz e Maria Helena Colameo Motta
}

Para a prevenção da doença de Chagas, em múltiplas regiões latino-americanas, é fundamental'que populações contem com adequadas condições sócio-econômicas e, especificamente, habitacionais, a fim de ficar coibida a veiculação do Trypanosoma cruzi através de triatomíneos. É preciso também não esquecer, profilaticamente, da participação de mecanismos alternativos de transmissão, mas atualmente, sem dúvida, ainda é indispensável manter em foco a necessidade de impedir a disseminação propriciada pelos insetos, nas moradias impróprias.

Variadas providências são usadas ou cogitadas com a finalidade de combater a participação dos triatomíneos e, entre elas, tem proeminência o emprego de inseticidas. Todavia, alternativas por vezes suscitam cogitações, figurando nesse contexto preparações obtidas a partir de vegetais.

Recentemente, veículo leigo de divulgação informou que pesquisadores da Fundação Instituto Oswaldo Cruz e da Universidade Federal Fluminense, do Rio de Janeiro, verificaram que substâncias das plantas cinamono e erva de Santa Maria agem prejudicando odesenvolvimento e a reprodução de triatomíneos, configu rando inseticidas naturais, biodegráveis e não tóxicos. Foi igualmente noticiado que tais èstudos contam com a cooperação de profissionais da Universidade do Arizona e do Instituto Max

Laboratório de Investigação Médica - Parasitologia, do Hospital das Clínicas, da Faculdade de Medicina da Universidade de São Paulo, São Paulo, SP.

Endereço para correspondência: Dra. Hertha Barbara Wüllert Telles de Souza, Laboratório de Investigação Médica - Parasitologia. Av. Dr. Arnaldo 455, 01246 São Paulo, SP, Brasil.

Recebido para publicação em 25/06/91
Planck de Bioquímica, sediados respectivamente nos Estados Unidos da América e na Alemanha, em Munique ("O Estado de S. Paulo", 16 de agosto de 1988, página 16$)$.

Interessamo-nos pelo assunto, efetuamos observação pertinente à erva de Santa Maria e, agora, comunicamos o resultado dessa apreciação. Ovegetal em questão (Chenopodium ambrosioides), amplamente presente em ruas, jardins e matas do Brasil ou outros países americanos é, em geral popularmente, usado em virtude de sua propriedade aromática, recorrendo-se à infusão elaborada com folhas quando desejados efeitos sedativos e emenagogo; além disso, o suco é anti-helmíntico que já gozou de bom prestígio e diz-se que com folhas frescas é viável constituir inseticida.

De início, com extrato de quenopódio comercial (Extrato fluido de erva Santa Maria "Farmácia e Laboratório As Plantas Curam Ltda."; Rua São Bento 351, São Paulo, Estado de São Paulo, Brasil), por meio de xenodiagnóstico in vitro' ${ }^{3}$, verificamos qual o teor máximo aceito pelos insetos. A sangue de ratos adicionamos concentrações crescentes e adotamos a quantidade de 250 microlitros para cada ml. Julgamos melhor não aumentar essa porção por temermos rejeição total, uma vez que o cheiro torna-se muito intenso.

Constituimos dois lotes com ninfas de terceiro estádio do Triatoma infestans, tendo um 60 exemplares e o outro 30 . Todos os insetos permaneceram 15 dias sem receber alimentação e, a seguir, efetuaram três repastos quinzenais. Os componentes do grupo maior ingeriram sangue e extrato, na composição estipulada de 250 microlitros/ $\mathrm{ml}$; os demais receberam apenas sangue. Nesta fase também recorremos ao xenodiagnóstico in vitro.

A fim de consumarmos nosso objetivo analisamos a evolução em cada conjunto, anotando mortalidade e ecdises, durante três meses. 
Comunicação. Souza HBWT, Amalo Neto V, Braz LMA, Motta MHC. Estudo sobre a eventual influência da erva de Santa Maria na evolução e mortalidade de triatomineos. Revista da Sociedade Brasileira de Medicina Tropical 24:183-184, jul-set, 1991

Nossas verificações estão adiante resumidas: triatomíneos mortos - 12 no lote de 60 (20\%) e nenhum no de 30; mudas para estádios subseqüentes - processaram-se sintematicamente no lote controle e entre os remanescentes vivos do superior.

Portanto, pelo menos conforme a metodologia adotada, não se afigurou promissor o quenopódio quando cogitado para influir na maturação sexual e perpetuação da espécie, no que tange aos hemípteros considerados. A pequena mortalidade, situada no limite do que se passa habitualmente nas criações em laboratório, ao lado da evolução não alterada, desestimulam a proposição profilática da tática alternativa assinalada.

\section{REFERÊNCIAS BIBLIOGRÁFICAS}

1. Campos R, Amato Neto V, Matsubara L, Moreira $\mathrm{AAB}$, Pinto PL S. Estudo sobre xenodiagnóstico "in vitro". I - Escolha de anticoagulante e de membrana. Revista do Hospital das Clínicas da Faculdade de Medicina da Universidade de São Paulo 43:101-103, 1988.

2. Peckolt P, Peckolt G. Historia das plantas medicinaes e uteis do Brazil. Typographia
Laemmert \& C., Rio de Janeiro p.1 369, 1888.

3. Souza HBWT, Moreira AAB, Matsubara L, Campos R, Amato Neto V, Pinto PLS, Takiguti CK. Estudo sobre o xenodiagnóstico "in vitro". II - Comparação com o xenodiagnóstico "in vivo". Revista do Hospital das Clínicas da Faculdade de Medicina da Universidade de São Paulo 43:165$167,1988$. 